\title{
THE APPLICABILITY OF DUAL POLARIZED SENTINEL-1 SAR DATA FOR DETECTION OF FLOODED AREAS IN POL-E DOKHTAR, LORESTAN, IRAN
}

\author{
N. Kianfar ${ }^{1}$ \\ ${ }^{1}$ Department of Surveying engineering, Faculty of civil engineering, Shahid Rajaee Teachers Training University, Tehran, \\ Nima.nkianfar@yahoo.com
}

KEY WORDS: flood detection, dual polarized, sentinel-1, Pol-e-Dokhtar, incidence angles

\begin{abstract}
:
The main source for acquiring enough information about the areas of flood for the purpose of quick mapping is Microwave remote sensing because of its capability of imaging even in serious conditions of weather. Sentinel-1 with HV polarization is way more practical than VV polarization for detecting the flooded area due to its sensivity to short ripples over the surface of the flood. Despite this privilege, at low incidence angles, the same difficulty is observed in HV polarization. In this research, the main focus is on extracting the flood inundation with dual polarized sentinel-1 data in high and low incidence angles. The extraction of backscatter values for flood surface in VV and also HV polarizations had been done. The backscatter from floodwater is high at low incidence angles and sometimes low at high incidence angles as is illustrated by Sentinel-1 HV polarized data. However, the alteration is marginal at those high and low incidence angles with using Sentinel-1 VV polarized data. A measurement between Sentinel-1 VV \& HV datasets and Optical Sentinel-2 had been done. The extension of flood is higher when we use Sentinel-2 as opposed to VV \& $\mathrm{HV}$ and also the flood extent from VV at low incidence angles is way lesser. Another observation is that even at diverse incidence angles, the combination of flood mapping from VV \& HV have the ability to compare with optical data much better.
\end{abstract}

\section{INTRODUCTION}

When a flood occurs, identifying flooded zones and estimating the destruction caused by flood is extremely hard with the use of ordinary procedures. Also, the type of process is of the utmost importance. As is observed, satellite remote sensing is beneficial in spatial mapping of inundated zones and identifying the flood demolition in recent years. Using spatial map of flood with data collected by satellite, is a superb method in order to deal with the harsh condition and also improve rescue operations when we want to manage the catastrophe. The most imperative part of a flood map is the flood layer. This should be observed from satellite data. However, explanation of flood layer is complicated in rainy seasons, since clouds cover the optical satellite data. Therefore, using a synthetic aperture radar (SAR) sensor is a great method for the purpose of managing activities and flood mapping as it is able to image in any serious condition of weather (Lee K S4, Lee S I4, 2003). However, as the strength of the radar-backscattered signal depends on some items such as angle, wavelength and polarization of the signal and also the geometric and electrical attributes of the target it impends upon, assessment of flood mapping alters with the type of polarization. In order to delineate flood mapping, the better way is using Sentinel-1 with HV polarization (David G2. et al. 1996). A lot of methods are used throughout the world to extract the flooded areas by using microwave data like thresholding method, object-oriented classification method, and active contour algorithm method (R. Heremans5, A. Willekens5, et al.). All mentioned algorithms consider the assumption that water is dark on the radar imagery, because the surface of water acts as a specular surface for microwave radiation which is reflected back in other direction, away from the sensor eventuating in low signal return. Nonetheless, some microwave radiation towards the antenna of sensor can be expected because of wind circumstances. As a result, the presence of brighter tones in the image is similar to non-flooded areas. It often may happen in VV polarization. However, sometimes, the same issue is detected in HV polarization at low incidence angles. Therefore, it is hard to separate it from other kinds of land cover. (Henry J. B3, Chasternet P3, et al. 2003). The primary purpose of the research is to check the description of flooded areas with dual polarized SAR data and also investigate the alteration in flood mapping in both $\mathrm{VV}$ and $\mathrm{HV}$ data which obtained at low \& high incidence angles. The other objective is to find out differences between flood extent extracted from dual polarized data and optical satellite data.

\section{MATERIAL}

\subsection{Study area}

Area of the study is located in Pol-e-Dokhtar, which is located in west of Iran as is illustrated by figure 1 . The city is famous for its ancient bridges. The name of this city is taken from the name of the great bridge that has been left behind by the Sasanian times. Currently, the destroyed pillars of the bridge, which are on the river, are visible and the congress that goes through the entire road below it, is still existing. The city of Pol-e-Dokhtar is located on the slopes of Mount Mullah, located in Zagros Mountain. Pol-e-Dokhtar is geographically located at $33^{\circ} 9^{\prime} 13^{\prime \prime} \mathrm{N}, 47^{\circ} 42^{\prime} 49^{\prime \prime} \mathrm{E}$, with an elevation of 650 meters to 710 meters above sea level. The city has hot weather in summer and it is moderate and relatively cold in winter.

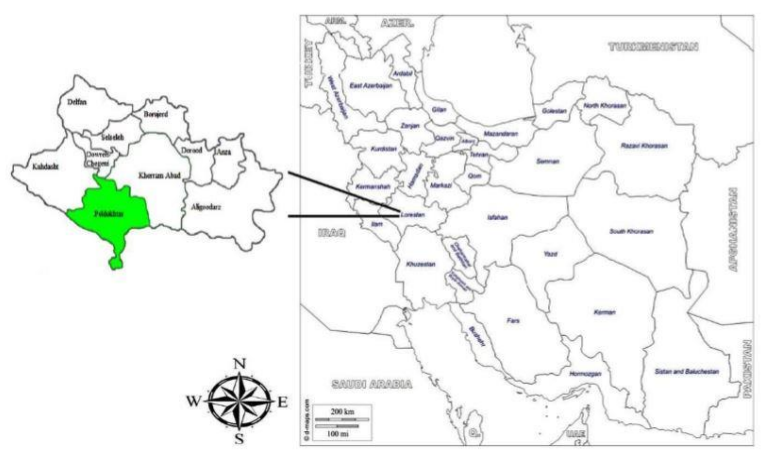

Figure 1. study area 


\subsection{Data set}

There are a number of applications for the data collected via Sentinel-1 mission. Recently, Sentinel-1 has worked in detection and monitoring flood inundated area. The details of the data obtained for the research are given in Table 1 below.

\begin{tabular}{|l|l|l|}
\hline $\begin{array}{l}\text { Satellite - } \\
\text { Sensor }\end{array}$ & $\begin{array}{l}\text { Acquisition Date, Time } \\
\text { (GMT) }\end{array}$ & Polarization \\
\hline Sentinel 1A & 20190406T145123 & VV \& HV \\
\hline Sentinel 1B & 20190331T145103 & VV \& HV \\
\hline Sentinel 2A & 20190404T073619 & ------ \\
\hline
\end{tabular}

Table 1. Sentinel-1 mission data

\section{METHODOLOGY}

The digital image of Sentinel-1 data was transformed to the backscattered image $(\sigma 0$ in $\mathrm{dB})$ for $\mathrm{VV}$ and $\mathrm{HV}$ polarization using the equation (1). Because all SAR images are created by a logical image system, they include speckle, which reduces the quality of the image. A 5 x 5 medial filter was applied on the image for deleting the speckle and was corrected geometrically with master pre-flood Sentinel-2 satellite data. During correction, considered to maintain the Root Mean Square (RMS) error lesser than 1 pixel and also for resampling, nearest neighbourhood method was used.

$$
\begin{array}{rl}
\operatorname{SIGMA}_{i j}=10.0 & * \log 10\left(\left(D N * D N+A_{0}\right) / A_{j}\right)+10.0 \\
& * \log 10\left(\sin \left(I_{j}\right)\right)
\end{array}
$$

$S I G M A_{i j}$ : output backscatter coefficient in decibels for scanline Table 1. Data obtained for the research

\section{$i$, pixel $j$}

$D N$ : input image value for scanline $i, \operatorname{pixel} j$

$A_{0}$ : gain offset from the first member of $A_{0} S E G$

$A_{j}$ : expanded gain scaling table value for column $j$

$I_{j}$ : extended incident angle table value for column $j$

The threshold method was adopted for water classification in microwave data, and also the threshold was defined by observing the $\sigma^{0}$ values at various flood pockets and river crosssections. The speckle reduced images were converted into binary images by replacing all pixels that are between the range of $\sigma^{0}$ values by a single value the same as one and those outside the given threshold range were replaced by zero. Nonetheless, darker areas contain flood, other smooth areas like sand, permanent water bodies and lakes. These zones were separated from inundated areas. Therefore, last classified layers produced were free from pre-flood river and water bodies, also comprised of just the flood extent. The variation in flood inundation pockets in $\mathrm{HV}$ and $\mathrm{VV}$ polarizations were measured and determined. In addition, VV and HV and combined VV and $\mathrm{HV}$ flood layers were compared with optical flood layer and circumstantial evidence of the flooded zones were determined. The difference was considered just for cloud-free patches in optical data.

\section{EXPERIMENTAL RESULT}

\subsection{Differences in flood extent at various incidence angles}

As is illustrated by Sentinel-1 VV polarized data, backscatter from floodwater at high incidence angles is low and also high at low incidence angles. However, in Sentinel-1 HV polarized data, the difference is marginal at high and low incidence angles. $\sigma 0$ for water was ranging between -24 and $-13 \mathrm{~dB}$ in $\mathrm{HV}$ polarization and also between -21 and $-9 \mathrm{~dB}$ in VV polarization at high incidence angles, while it was different between -29 and $-15 \mathrm{~dB}$ in $\mathrm{HV}$ and between -24 and $0 \mathrm{~dB}$ in $\mathrm{VV}$ at low incidence angles. Spectral shows that $\sigma 0$ from water surface in $\mathrm{HV}$ polarization is lesser as opposed to that of $\mathrm{VV}$ polarization at transects L1 \& L2. A big contrast between HV and VV polarizations due to water feature at low incidence angles is obvious. The mean of $\sigma 0$ for water in $\mathrm{VV}$ and $\mathrm{HV}$ is different between -25.24 and -11.61 and between -21.90 and -22.33 respectively across transects L1 \& L2. The normal deviation of $\sigma 0$ for water is different between 2.22 and $7.25 \mathrm{~dB}$ in $\mathrm{HV}$ and also between 7.55 and $8.65 \mathrm{~dB}$ for $\mathrm{VV}$ across river transects $\mathrm{L} 1$ \& L2. In VV \& HV polarization images and spectral profile at high incidence angles, the variance in $\sigma 0$ in VV and $\mathrm{HV}$ is not significant. Normal deviation of $\sigma 0$ for water is different between 1.72 and $2.10 \mathrm{~dB}$ in $\mathrm{HV}$ and between 1.49 and $2.80 \mathrm{~dB}$ in case of VV across river transects L1 \& L2 respectively.

\subsubsection{The distinctions in flooded area between VV and HV polarizations}

The water class was extracted from VV and HV of Sentinal-1 data. The Sentinel-1 image of 06-Apr-19 of VV polarization, according to flood layer. The whole flooded area was 27.67 Sq.Km. The Sentinel-1 image of 06-Apr-19 of HV polarization, according to flood layer. The whole flooded area was 50.48 Sq.Km. The difference in flooded area is significant. As opposed to other research done in this field of study, results are extremely similar to them in terms of differences in flood mapping from $\mathrm{VV}$ and $\mathrm{HV}$ polarizations.

\subsubsection{The differences in flood mapping between $\mathrm{VV}$ and $\mathrm{HV}$}

Sentinel-1 data of 31-Mar-19 was analysed to search the differences in the backscattered energy between VV and HV polarizations at higher incidence angles. The inundated area was estimated to be $78.24 \mathrm{Sq} \mathrm{Km}$ in VV and 79.10 Sq.Km in HV. The sentinel-1 image of 31-Mar-19 VV and HV with corresponding flood layers respectively. The difference in the inundated area is not significant. Since concurrent optical data was not available over the study area, here the flood mapping was not compared with optical data.

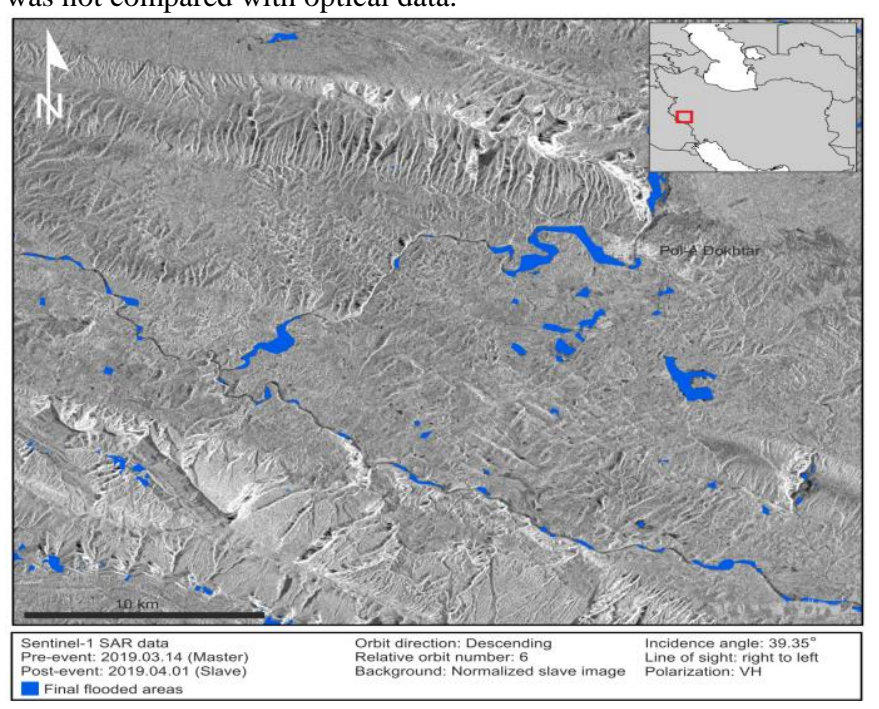

Figure 2. Final flooded areas using sentinel-1 SAR data 


\subsection{The differences in flood mapping between $\mathrm{VV}$ and $\mathrm{HV}$ and Sentinel 2 data}

The water class was extracted from VV and HV and Sentinel 2 image and the Sentinel 2 satellite image of the research zone and its communicating to three layers: flood, cloud and cloud shadow. There is an overlap of cloud shadow and water signature in the image. Therefore, it should be edited and also the final layer was generated. The whole area of flood was measured and the result is $61.37 \mathrm{Sq} . \mathrm{km}$. The same process was adopted for HV image. The Sentinel-1 image of 06-Apr-19 of HV polarization, corresponding flood layer in the cloud-free areas. The whole flooded area was about $40.63 \mathrm{Sq} . \mathrm{Km}$, that is $68 \%$ of the zone.

\section{CONCLUSION}

This research illustrates that Sentinel-1 data at low and high incidence angles were used to calculate the differences in the backscattered intensity in flooded area. Corresponding Sentinel 2 data was also analysed to compare the flooded area. Obviously, the combined inundation of $\mathrm{VV}$ and $\mathrm{HV}$ is comparable with optical data irrespective of incidence angles. The flood mapping acquired from VV image is way lesser than optical data at low incidence angles. Nonetheless, by using VV and $\mathrm{HV}$ polarizations at the same time, flood mapping is more than $89 \%$, at low incidence angles when compared with Sentinel 2 results. Therefore, dual polarized Sentinel-1 SAR data is way better for describing the flooded areas than single polarized SAR, and also it is much more practical than other methods due to its capability of flood mapping.

\section{REFERENCES}

Bhanumurthy V, Srinivasa Rao G, Simhadri Rao B, Manjusree P, "A System for Survival, Geospatial Today," Vol 2, Issue 2, 30-33, Jul-Aug 2003.

David G. Barber, Klaus P.Hochheim, Roy Dixon, David R. Mosscrop, Michael J. Mcmullan, "The Role of Earth Observation Technologies in Flood Mapping: A Manitoba case study," Canadian Journal of Remote Sensing, Vol. 22, No.1, March 1996.

Henry J.B, Chastanet P, Fellah K, Desnos Y.L, "Envisat MultiPolarized ASAR data for Flood Mapping," Proceedings of IGARSS'03, 1136-1138, Toulouse, France, 2003.

Lee K S, Lee S I, "Assessment f post flooding conditions of rice fields with multi-temporal satellite SAR data," INT. J. Remote Sensing, Vol. 24, No.17, 3457-3465, 2003.

R. Heremans, A. Willekens, D. Borghys, B. Verbeeck, J. Valckenborgh, M. Acheroy, C. Perneel, "Automatic detection of flooded areas on ENVISAT/ASAR images using an objectoriented classification technique and an active contour algorithm,"

Vishwas S. Kale, Flood Studies in India, Memoir 41, Geological Society of India, Bangalore, 1998 